\title{
Effect of particle size on adsorption of heavy metals using chemically modified and unmodified fluted pumpkin and broad-leafed pumpkin pods
}

\author{
Sunday O. EZE, Jude C. IGWE* and Darlington DIPO \\ Department of Industrial Chemistry, Faculty of Biological and Physical Sciences, Abia State University, \\ P.M.B. 2000 Uturu, Abia State, Nigeria. \\ *Corresponding author, E-mail: jcigwe2001@yahoo.com, Tel: +234-803-675-2059
}

\begin{abstract}
The effect of particle size on the bioremediation of $\mathrm{Pb}(\mathrm{II}), \mathrm{Zn}$ (II), $\mathrm{Cd}$ (II) and $\mathrm{Hg}$ (II) ions from synthetic aqueous effluents using unmodified and carboxymethylated fluted pumpkin and broad-leafed pumpkin pods was investigated in a batch system. $1.2 \mathrm{~g}$ of adsorbents was used in each sorption experiment at $25^{\circ} \mathrm{C}$ and $\mathrm{pH}$ 6.5-8.5 for one hour interval. The results showed that the two adsorbents were good for the removal of these metal ions. Unmodified fluted pumpkin pod was found to be better than the other tested adsorbents with removal efficiencies of $92.62 \%, 81.88 \%, 75.21 \%$ and $49.67 \%$ for $\mathrm{Pb}$ (II), $\mathrm{Zn}$ (II), Cd (II) and $\mathrm{Hg}$ (II), respectively. Carboxymethylation decreased the adsorption capacity of the cellulose materials mostly for fluted pumpkin pod. Particle size below $600 \mu \mathrm{m}$ was found to be the optimum size for unmodified absorbent, while 600-1000 $\mu \mathrm{m}$ was observed for modified adsorbent. Fluted pumpkin pod was found to be a more effective adsorbent for these metal ions than the broad leafed pumpkin pod especially when unmodified. Therefore these results show that fluted pumpkin and broad-leafed pumpkin pods could serve as very good adsorbents in the treatment of these metal ions from aqueous effluents.
\end{abstract}

(C) 2013 International Formulae Group. All rights reserved.

Keywords: agricultural waste, bioremediation, heavy metals, pollution control, surface chemistry.

\section{INTRODUCTION}

Environmental pollution problems caused by heavy metals cannot be over emphasized. Heavy metals are very toxic and pose a threat to man and the environment. High concentration of heavy metal in the environment can be detrimental to a variety of living species (Onundi et al., 2010). Some heavy metals normally occurring in nature are not harmful because they are only present in very small amounts. Living organisms require trace amounts of some of these heavy metals including iron, cobalt, copper, manganese, molybdenum, vanadium, strontium and zinc but excessive levels can be detrimental to the organisms (Ikhuoria and Omonmhenle, 2006). Whereas, other heavy metals such as mercury, lead, and cadmium have no known vital or beneficial effect on living organisms, their accumulation in the environment causes serious environmental and ecosystem imbalance, hence results to different kinds of adverse health conditions (Issabayeva et al., 2007; Onundi et al., 2010) Carcinogenesis, kidney damage, neurological disorder, blindness, damage to aquatic resources, nervous disorder, and so on are some of the problems caused by these bioaccumulating and non-biodegradable heavy metal pollutants. It has been reported that excessive 
ingestion of these metals by humans can cause accumulative poisoning, cancer, nervous system damage and ultimately death (Issabayeva et al., 2007).

Therefore, the elimination of heavy metals from the environment is important as a result of their high toxicity and at least to protect public health (Abdel-Ghani and ElChaghaby, 2007; Abdel-Ghani et al., 2009; Resmi et al., 2010). Many researchers have reported the removal of these heavy metals using several physicochemical methods such as chemical precipitation, evaporation, ion exchange, and reverse osmosis (Ikhuoria and Omonmhenle, 2006). However, these conventional technologies appear to be inadequate and expensive. Over the last few years sorption have been shown to be an economically feasible alternative method for removing metal ions (Uzun and Güzel, 2000; Qadeer and Akhtar, 2005; Onundi et al., 2010; Okoye et al., 2010).

As a result of the toxic effects of heavy metals and the disadvantages of conventional methods of removal, a great deal of interest in the research for the removal of heavy metals from industrial effluents (or other sources) have focused on the use of agricultural byproducts as adsorbents. The sorption of heavy metal pollutants using agricultural waste is an innovative method which has attracted a lot of attention in the past few years to control and detoxify heavy metal pollutants. Some of the agricultural by-products that have been reported includes maize cob and husk (Igwe and Abia , 2003, 2005; Opeolu et al., 2009), maize tassel (Zvinowanda et al., 2009), sawdust (Urik et al., 2009; Kaczala et al., 2009; Vinodhini and Das, 2009, 2010), cassava waste (Horsfall et al., 2003), coconut fiber (Igwe et al., 2007, 2011), cocoa pod husk (Igwe et al., 2011), boiler fly ash (Okoronkwo et al., 2008). Fluted pumpkin have been reported as an adsorbent for heavy metal ions from aqueous solutions (Ikhuoria and Omonmheale, 2006; Okoye et al., 2010).

Also, several parameters have been investigated as factors in adsorption studies, such as effect of initial concentration of adsorbates, effect of contact time of sorption, and so on. Therefore, in this work, we report on the effect of particle size of adsorbent on the sorption capacities of modified and unmodified fluted pumpkin and broad-leafed pumpkin pods.

\section{MATERIALS AND METHODS Materials}

Fluted pumpkin (Telfairia occidentalis) and broad-leafed pumpkin (Curcurbita sp.) pods were collected from a local farm in Isiala Ngwa south, Abia State, Nigeria and was properly identified at the Department of Plant Science and Biotechnology, Abia State University, Uturu, Nigeria. Lead nitrate $(\mathrm{Pb}$ $\left.\left(\mathrm{NO}_{3}\right)_{2}\right)$; mercury (II) chloride $\left(\mathrm{HgCl}_{2}\right) 98 \%$; hydrated zinc sulphate $\left(\mathrm{ZnSO}_{4} .7 \mathrm{H}_{2} \mathrm{O}\right) 99 \%$ and hydrated cadmium chloride $\left(\mathrm{CdCl}_{2} .2 \mathrm{H}_{2} \mathrm{O}\right)$ 99\% were used to prepare the respective metal ions solutions. All chemicals used were analytically grades, purchased and used without further purification.

\section{Methods \\ Adsorbent preparation}

The adsorbents were washed, cut into small pieces, air dried and powdered in a grinder. The meal obtained were air-dried and each was first sieved through $1200 \mu \mathrm{m}$ mesh; secondly through $850 \mu \mathrm{m}$; thirdly through 600 $\mu \mathrm{m}$ and then through $400 \mu \mathrm{m}$ size. The meal retained between the particle size ranges of 1200-850 $\mu \mathrm{m}, 850-600 \mu \mathrm{m}$ and 600-400 $\mu \mathrm{m}$ was used. Each of them was socked in dilute acid solution $\left(\mathrm{HNO}_{3}, 2 \% \mathrm{v} / \mathrm{v}\right)$ for $24 \mathrm{hrs}$ at room temperature. After that, each of the adsorbents were rinsed with deionized water, air-dried and divided into two parts, one part was stored for use and the second part was modified by carboxymethylation.

One portion of the activated adsorbents was modified by carboxymethylation (Ragheb et al., 1989). $100 \mathrm{~g}$ of the adsorbent were added to a mixture of $650 \mathrm{ml}$ ethyl alcohol and $554 \mathrm{ml}$ toluene, a $50 \%$ solution of sodium hydroxide $(33 \mathrm{ml})$ was added in $1 \mathrm{~min}$ and followed by gradual addition of $25 \mathrm{~g}$ of monochloroacetic acid. The reaction mixture was kept at $65{ }^{\circ} \mathrm{C}$ for $70 \mathrm{~min}$ with agitation and left over night. The excess sodium hydroxide solution was neutralized with glacial acetic acid. The carboxymethylated 
adsorbents were filtered, washed with ethyl alcohol and purified by extraction with ethyl alcohol.

\section{Sorption of metal ions}

The sorption of the metal ions was carried out with initially prepared concentration of $100 \mathrm{mg} / \mathrm{l}$ of the metal ions ( $\mathrm{Pb}$ (II), Zn (II) Cd (II) and Hg (II)) solutions. It was put into reagent bottles containing $1.2 \mathrm{~g}$ of adsorbent. The reagent bottles were corked and constantly shaken in a rotary shaker for 1 $\mathrm{hr}$ at $\mathrm{pH}$ of 7.5 and temperature of $25{ }^{\circ} \mathrm{C}$. Thereafter, the contents of the reagent bottle were centrifuged at $3500 \mathrm{rpm}$ and the supernatant rapidly filtered through a Whatman No. 41 filter paper into sample bottles for analysis. The same procedure was used with all the four metal ions solutions with modified and unmodified adsorbent of the different particle sizes. The metal ion contents of all the filtrates, the four initial prepared concentrations of metal ions solutions and blank metal ions solutions without the adsorbents, were analyzed with the aid of an Atomic Absorption Spectrophotometer (AAS) UNICAM 919 model. The concentrations of each metal ions adsorbed by each adsorbent were calculated from the difference between the analyzed initial metal ion concentration of each prepared metal ion solution $\left(\mathrm{C}_{\mathrm{o}}\right)$ and the concentration after adsorption $\left(\mathrm{C}_{\mathrm{e}}\right)$.

The soaking of the adsorbent in $2 \%$ $(\mathrm{v} / \mathrm{v})$ nitric acid served to activate the adsorbent and wash of any soluble biomolecules that may interfere with adsorption process. The amount of metal ions adsorbed was calculated by a modified mass balance equation as follows (Chu and Hashim, 2001; Ho and Wang, 2004): $\mathrm{q}_{\mathrm{e}}=\mathrm{V}\left(\mathrm{C}_{\mathrm{o}}-\mathrm{C}_{\mathrm{e}}\right) / \mathrm{m}$ (1) where $\mathrm{q}_{\mathrm{e}}$ is the equilibrium amount adsorbed (mg/g); $\mathrm{C}_{\mathrm{e}}$ is the equilibrium amount $(\mathrm{mg} / \mathrm{l})$ remaining in solution; $\mathrm{C}_{\mathrm{o}}$ is the initial concentration $(\mathrm{mg} / \mathrm{l})$ of metal ion solution; $\mathrm{V}$ is the volume $(\mathrm{ml})$ of metal ion solution used and $\mathrm{m}$ is the mass ( $\mathrm{g}$ ) of adsorbent used. Then, the percentage of the metal ions adsorbed was calculated from the equation below: $\% \mathrm{q}_{\mathrm{e}}=100 \times\left(\mathrm{C}_{\mathrm{o}}-\mathrm{C}_{\mathrm{e}}\right) / \mathrm{Co}=100 \times \mathrm{q}_{\mathrm{e}} / \mathrm{Co}$

The prepared stock solutions of the metal ions were analyzed and the initial concentration of the metal ion solutions $\left(\mathrm{C}_{\mathrm{o}}\right.$ $\mathrm{mg} / \mathrm{l}$ ) of $\mathrm{Pb}$ (II) $\mathrm{Zn}$ (II) $\mathrm{Cd}$ (II) and $\mathrm{Hg}$ (II) was found to be $92.50 \mathrm{mg} / \mathrm{l}, 89.87 \mathrm{mg} / \mathrm{l}, 93.25$ $\mathrm{mg} / \mathrm{l}$ and $94.35 \mathrm{mg} / \mathrm{l}$ respectively. The difference between the $100 \mathrm{mg} / \mathrm{l}$ prepared and the values obtained above may likely be due to impurities in the individual metal salts, the sensitivity of the AAS or the error in weighing and preparing the stock solutions. The percentage amount adsorbed $\left(\begin{array}{ll}\% & \mathrm{q}_{\mathrm{e}}\end{array}\right)$ was calculated from the initial $\left(\mathrm{C}_{\mathrm{o}}\right)$ and final $\left(\mathrm{C}_{\mathrm{e}}\right)$ concentration analyzed using AAS.

\section{RESULTS}

The effect of particle size on adsorption of the metal ions onto the adsorbents, unmodified fluted pumpkin pods (UFPP), unmodified broad leafed pumpkin pods (UBLPP), modified fluted pumpkin pods (MFPP) and modified broad leafed pumpkin pods (MBLPP), are shown in Figures 1- 4 respectively. The particle size varies with surface area, and with the number of micropores. Since sorption is particle diffusion controlled, the increase in micropore increases the number of accessible sites, hence increases the amount adsorbed.

The amounts adsorbed follow the order 400-600>600-850> 850-1200 $\mu \mathrm{m}$ for unmodified adsorbents with few variations. $\mathrm{Pd}(\mathrm{II})$ ions were adsorbed more on UFPP of particle size $400-600 \mu \mathrm{m}$. For the modified adsorbent, $\mathrm{Zn}$ (II) was adsorbed more than the other metal ions. For modified adsorbents, the amount of metal ions adsorbed follow the order $\mathrm{Zn}$ (II) $>\mathrm{Pb}$ (II) $>\mathrm{Cd}$ (II) $>\mathrm{Hg}$ (II), while for the unmodified adsorbents the trend is $\mathrm{Pb}(\mathrm{II})>\mathrm{Zn}(\mathrm{II})>\mathrm{Cd}(\mathrm{II})>\mathrm{Hg}(\mathrm{II})$. The results indicated that the amount adsorbed by each individual particle size showed that 400-600 $\mu \mathrm{m}$ particle size give optimum condition for effective adsorption on unmodified adsorbent, while for the modified adsorbent; 850-1200 $\mu \mathrm{m}$ particle size gave higher sorption capacity. 


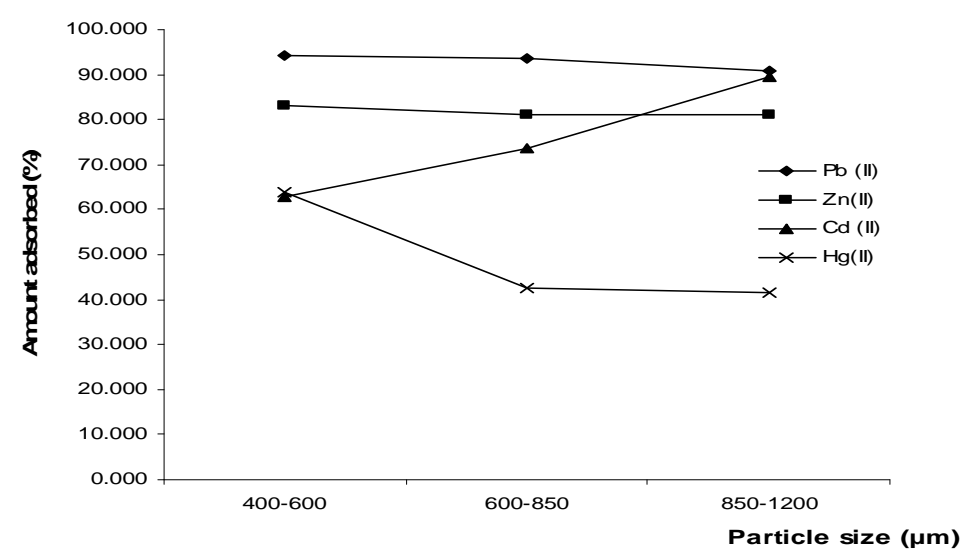

Figure 1: Percent adsorbed \% against particle size $(\mu \mathrm{m})$ for adsorption of $\mathrm{Pb}$ (II), $\mathrm{Zn}$ (II), $\mathrm{Cd}$ (II), and $\mathrm{Hg}$ (II) onto unmodified fluted pompkin pods (UFPP).

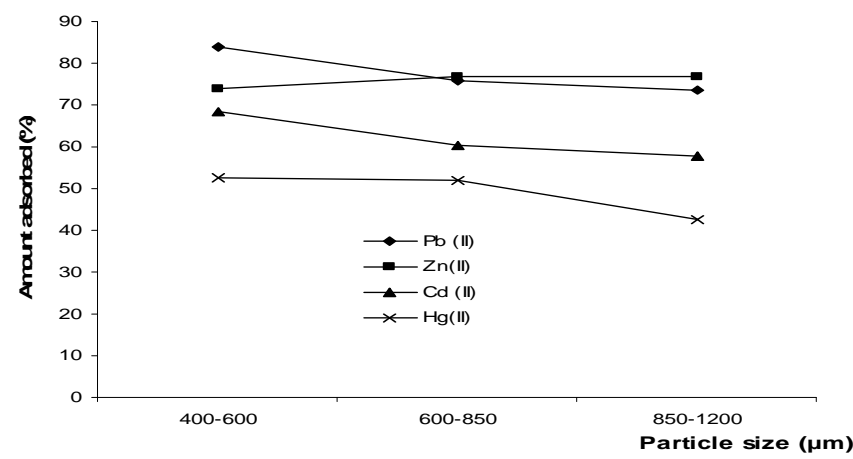

Figure 2: Percent adsorbed \% against particle size ( $\mu \mathrm{m})$ for adsorption of $\mathrm{Pb}$ (II), $\mathrm{Zn}$ (II), Cd (II), and $\mathrm{Hg}$ (II) onto unmodified broad leafed pompkin pods (UBLPP).

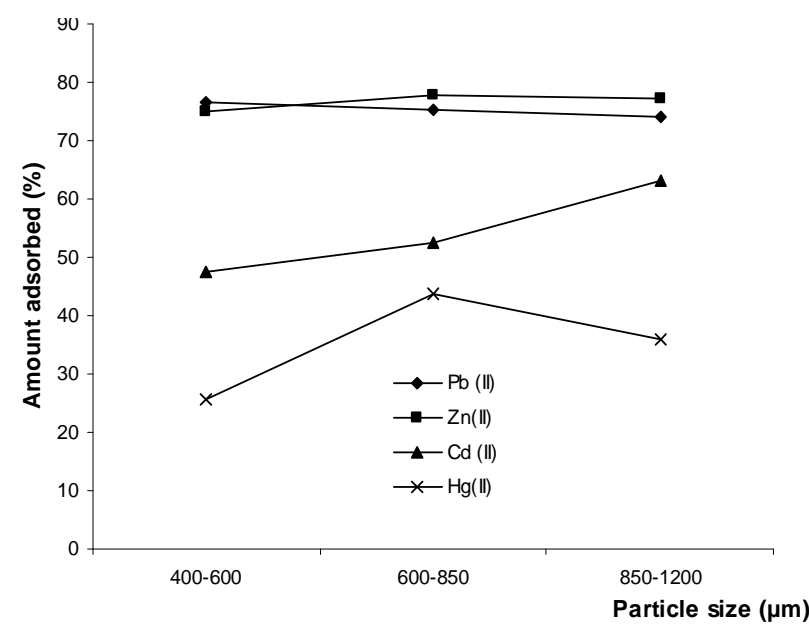

Figure 3: Percent adsorbed \% against particle size $(\mu \mathrm{m})$ for adsorption of $\mathrm{Pb}$ (II), $\mathrm{Zn}$ (II), Cd (II), and $\mathrm{Hg}$ (II) onto modified fluted pompkin pods (MFPP). 


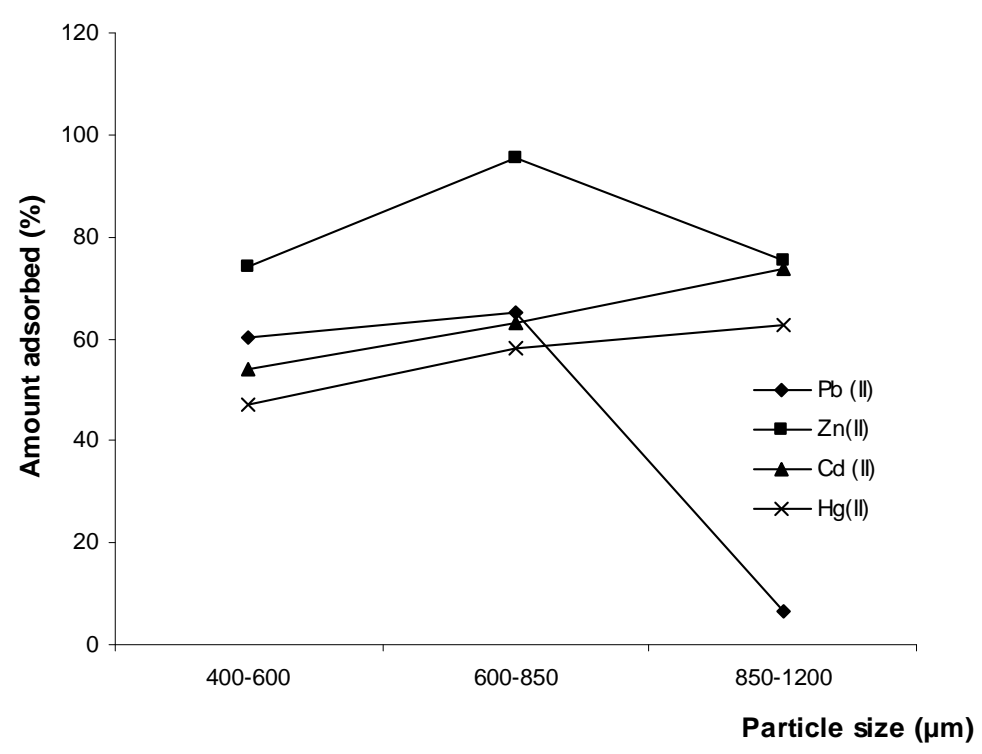

Figure 4: Percent adsorbed \% against particle size $(\mu \mathrm{m})$ for adsorption of $\mathrm{Pb}(\mathrm{II}), \mathrm{Zn}(\mathrm{II}), \mathrm{Cd}$ (II), and $\mathrm{Hg}$ (II) onto modified broad leafed pompkin pods (MBLPP).

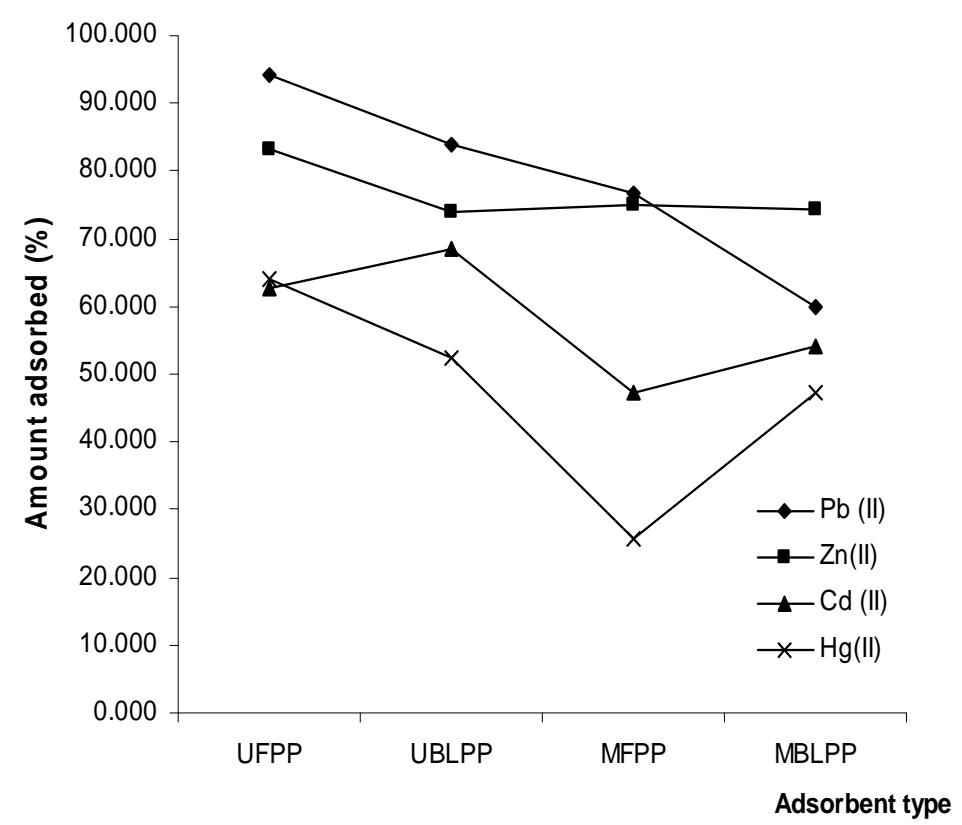

Figure 5: Percent adsorbed \% for adsorption of $\mathrm{Pb}$ (II), $\mathrm{Zn}$ (II), $\mathrm{Cd}$ (II), and $\mathrm{Hg}$ (II) onto the different adsorbent types for particle size of $400-600 \mu \mathrm{m}$. 


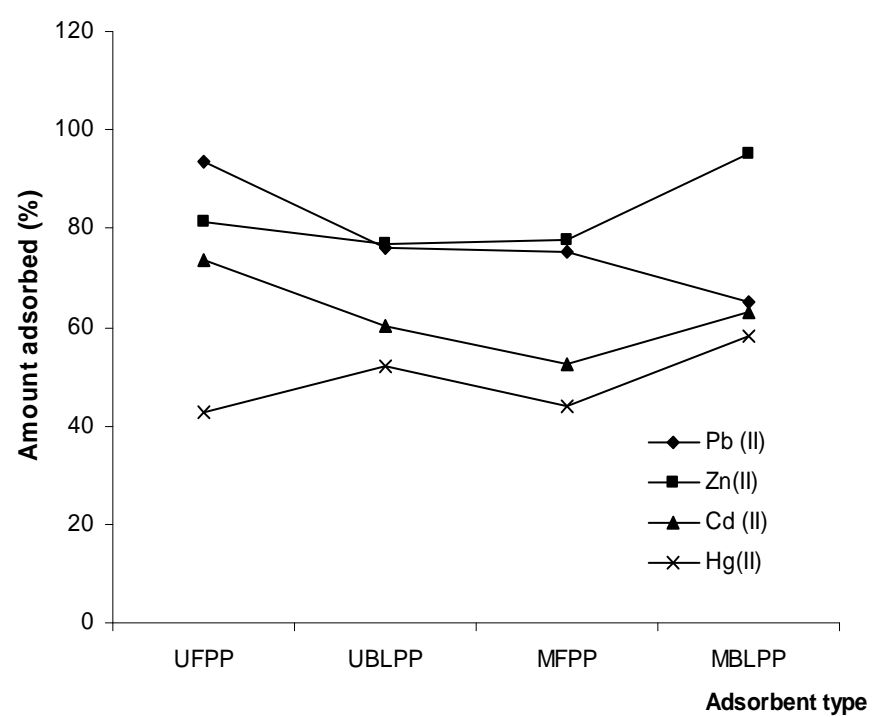

Figure 6: Percent adsorbed \% for adsorption of $\mathrm{Pb}$ (II), $\mathrm{Zn}$ (II), Cd (II), and $\mathrm{Hg}$ (II) onto the different adsorbent types for particle size of $600-850 \mu \mathrm{m}$.

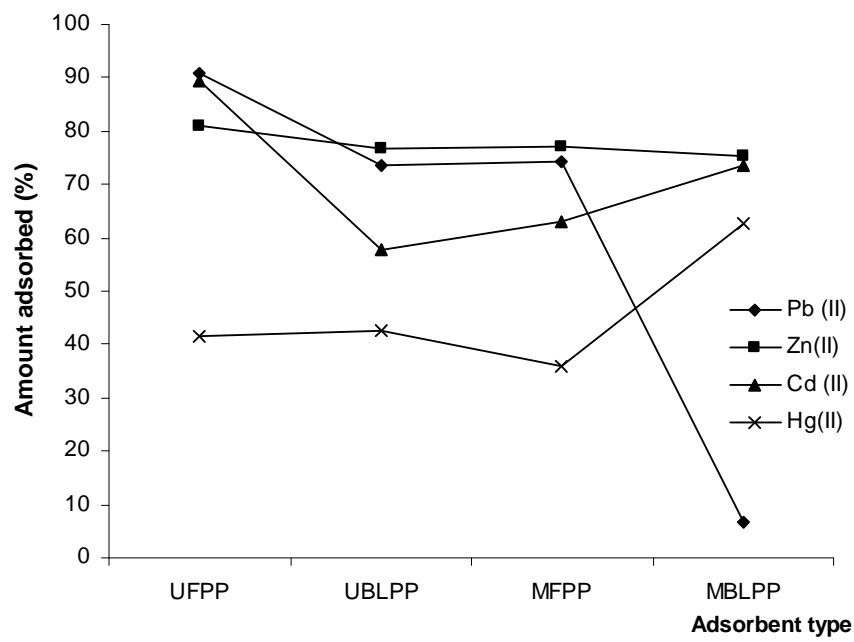

Figure 6: Percent adsorbed \% for adsorption of $\mathrm{Pb}$ (II), $\mathrm{Zn}$ (II), $\mathrm{Cd}$ (II), and $\mathrm{Hg}$ (II) onto the different adsorbent types for particle size of 850-1200 $\mu \mathrm{m}$.

\section{DISCUSSION}

The differences in the adsorption of the metal ions from aqueous solutions have been ascribed to some factors (Ho et al., 1995): (i) sizes of metal ions, (ii) affinity of the metal ions for some active groups on the biomass and (iii) nature of anions of the salt of the metals. It could be seen from the results of this work that the interplay of these factors has not produced a common trend for the metal ions on the adsorbents. The effect of particle size on adsorption of the metal ions from aqueous solutions has been reported by previous workers (Kuyucak and Volesky, 1989; Yang and Volesky, 1999). Eneida et al. (2002) reported that the size grading of ground biomass particles by standard sieves works on the length and width dimensions. Hence, the result of opposite trends on particle size effect. Similar to the results of this work, 
it has been found that smaller particle sizes gave higher adsorption capacities (Ho et al., 2002; Saueprasearsit et al., 2010). This may be attributed to the higher external surface available with smaller particles at a constant total mass.

Besides adsorption at the outer surface of the adsorbent, there is also the possibility of intraparticle diffusion from the outer surface into mass transfer, which is greater for large particles. As a result of various factors, such as diffusion part length or mass transfer resistance, contact time and blocked sections of the particle may not be utilized for adsorption, therefore, the adsorption capacity of large particles may be low (RomeroGonzalez et al., 2001; Shukla et al., 2002; Ngeontae et al., 2007).

For effect of modification on the sorption processes, Figure 5 shows the percent adsorbed versus the different adsorbents for particle size of 400-600 $\mu \mathrm{m}$ while Figure 6 and Figure 7 shows that for particle size of $600-850 \mu \mathrm{m}$ and $850-1200 \mathrm{um}$ respectively. It could be seen that modification by carboxymethylation decreased the adsorptive capacity of the adsorbents. Modification of adsorbent has been reported to alter the surface characteristics of the adsorbent (Horsfall et al., 2003; Chen and Yang, 2005). Although most modifications are known to improve the sorption capacity of the adsorbent, some modifications result in masking or inhibitory tendencies and thereby reduce the sorption capacity. Therefore, the modification of the adsorbent by carboxymethylation which introduced the group $-\mathrm{COCH}_{3}$ onto the surface of the adsorbent reduced the sorption capacity. The reduction in the amount adsorbed as affected by modification means that the carboxymethyl group blocks some of the micro pores, making it difficult for the metal ions to reach the adsorption sits. This is similar to the result obtained with maize cob and husk (Igwe et al., 2005). Other modification methods have also been reported such as; EDTA (Igwe and Abia, 2007), thiolation (Abia and Asoquo 2006; Akaninwor et al., 2007; Igwe et al. 2008), formaldehyde, glutaraldehyde and $\mathrm{HCl}$ (Chen and Yang, 2005), Urea and ferric Fe (III) oxhydroxides (Urik et al., 2009).

\section{Conclusion}

Fluted pumpkin and broad leafed pumpkin pods are all agricultural wastes and cause environmental pollution. They have been found to be good adsorbent for the removal of $\mathrm{Pb}^{2+}, \mathrm{Cd}^{2+}, \mathrm{Zn}^{2+}$ and $\mathrm{Hg}^{2+}$ from aqueous effluents. It was seen that modification by carboxymethylation decreased the adsorptive capacity of the cellulose materials mostly in fluted pumpkin pod. Also when unmodified, the adsorbent with particle size 400-600 $\mu \mathrm{m}$ adsorbed more but when modified, the particle size of 850$1200 \mu \mathrm{m}$ adsorbed more. Furthermore, fluted pumpkin pod is more effective than broad leafed pumpkin pod especially when unmodified. This was attributed to its high degree of micropores and very low weight per volume ratio. The increasing order of adsorbtivity based on each particular metal ion is as follows:

$\mathrm{Pb}$ (II) ion: UFPP> UBLPP> MFPP> MBLPP Zn (II) ion: UFPP> MFPP> UBLPP> MBLPP $\mathrm{Cd}$ (II) ion: UFPP> MPLPP> UBLPP> MFPP.

$\mathrm{Hg}$ (II) ion: MBLPP> UFPP> UBLPP> MFPP.Therefore, this innovative method of detoxifying/treating non-biodegradable pollutants (heavy metals) is found to be a good means of getting rid of heavy metal bearing effluent and that particle size affected the sorption capacity.

\section{REFERENCES}

Abdel-Ghani NT, El-Chaghaby GA. 2007. Influence of operating conditions on the removal of $\mathrm{Cu}, \mathrm{Zn}, \mathrm{Cd}$ and $\mathrm{Pb}$ ions from wastewater by adsorption. Int. J. Environ. Sci. Tech., 4(4): 451-456.

Abdel-Ghani NT, Hegazy AK, El-Chaghaby GA. 2009. Typha domingensis leaf powder for decontamination of aluminum, iron, zinc and lead: Biosorption kinetics and equilibrium modeling. Intern. J. Environ. Sci. Tech., 6(2): 243-248.

Abia AA, Asuquo ED. 2006. Lead (II) and Nickel (II) adsorption kinetics from aqueous metal solutions using chemically 
modified and unmodified agricultural adsorbents. Afr. J. Biotechnol., 5(16): 1475-1482.

Akaninwor JO, Wegwu MO, Iba IU 2007. Removal of iron, zinc and magnesium from polluted water samples using thioglycolic modified oil-palm fibre. Afr. J. Biochem. Res., 1(2): 011-013.

Chen JP, Yang L. 2005. Chemical modification of sargassum sp. For Prevention of organic leaching and Enhancement of uptake during metal biosortion. Ind. Eng. Chem. Res., 44: 9931-9942.

Chu KH, Hashin MA. 2001. Desorption of copper from polyvinyl alcohol immobilized seaweed biomass. Acta Biotechnol., 21(4): 295-306.

Eneida SC, Tavares CRG, Ravagnani TMK. 2002. Biosorption of Chromium (III) by Sargassum sp. Biomass. Elect. J. Biotechnol., 15(2): 133-140.

Ho YS, Huang CT, Huang HW. 2002. Equilibrium sorption isotherm for metal ions on tree fern. Proc. Biochem., 37: 1421-1430.

Ho YS, Wang CC. 2004. Pseudo-isotherms for the sorption of cadmium ion onto tree fern. Proc. Biochem., 39: 759-763.

Ho YS, Wase DAJ, Forster CF. 1995. Batch nickel removal from aqueous solution by sphagnum moss peat. Water Research, 29(5): 1327 - 1332.

Horsfall MJ, Abia AA, Spiff AI. 2003. Removal of $\mathrm{Cu}$ (II) and $\mathrm{Zn}$ (II) ions from wastewater by cassava (Manihot esculenta Cranz) waste biomass. Afr. J. Biotechnol., 2(10): 360-364.

Igwe JC, Abia AA. 2007. Adsorption isotherm studies of $\mathrm{Cd}$ (II) $\mathrm{Pb}$ (II) and $\mathrm{Zn}$ (II) ions bioremediation from aqueous solution using unmodified and EDTA-modified maize cob. Ecletica Quimica, 32(1): 3342.

Igwe JC, Abia AA. 2003. Maize Cob and Husk as Adsorbents for removal of $\mathrm{Cd}$, $\mathrm{Pb}$ and $\mathrm{Zn}$ ions from wastewater. The Phy. Sci., 2: 83-94.

Igwe JC, Abia AA. 2005. Sorption kinetics and intraparticulate diffusivities of $\mathrm{Cd}, \mathrm{Pb}$ and $\mathrm{Zn}$ ions on maize cob, $\mathrm{Pb}$ and $\mathrm{Zn}$ ions on maize cob. Afr. J. Biotechnol., 4(6): 509-512.

Igwe JC, Abia AA, Ibeh CA. 2008. Adsorption kinetics and intraparticulate diffusivities of $\mathrm{Hg}$, $\mathrm{As}$ and $\mathrm{Pb}$ ions on unmodified and thiolated coconut fiber. Intern. J. Environ. Sci. Tech., 5(1): 83-92.

Igwe JC, Abia AA, Okereke FH. 2011. Kinetic Studies on the sorption of $\mathrm{Ag}^{+}$ and $\mathrm{Al}^{3+}$ from aqueous solutions by Coconut fibre. Terrestrial Aquat. Environ. Toxicology, 5(1): 19-24.

Igwe JC, Nwokennaya EC, Abia AA. 2005. The role of $\mathrm{pH}$ in heavy metal detoxification by biosorption from aqueous solution containing chelating agents. Afr. J. Biotechnology, 4(10): 1109-1112.

Ikhuoria EU, Omonmhenle SI. 2006. Removal of Heavy metals from aqueous solution by adsorption onto chemically modified pumpkin (Telfairia occedentalis Hook) seed husk. J. Chem. Soc. Nig. 31 (1/2): 109-113.

Issabayeva G, Aroua MK, Sulaiman NM. 2007. Continuous adsorption of lead ions in a column packed with palm shell activated carbon. J. Hazard. Mater. 155(1-2): 109-113.

Kaczala F, Marques M, Hogland W. 2009. Lead and vanadium removal from a real industry wastewater by gravitation settling/sedimentation and sorption onto Pinus sylvestris sawdust. Bioresource Technol., 100: 235-243.

Kuyucak N, Volesky B. 1989. Accumulation of Cobalt by marine algae. Biotechnol. Bioeng., 33(7): 809-814.

Ngeontae W, Aeungmaitrepiron W, Tuntulani T. 2007. Chemically modified silica gel with aminothioamidoanthraquinonen for solid phase extraction and preconcentration of $\mathrm{Pb}(\mathrm{II}), \mathrm{Cu}(\mathrm{II}), \mathrm{NI}(\mathrm{II})$, $\mathrm{Co}(\mathrm{II})$ and $\mathrm{Cd}(\mathrm{II})$. Talanta, 71(3): 10751082.

Okoronkwo NE, Igwe JC, Ogbonna HI. 2008. Detoxification of $\mathrm{Hg}^{2+}, \mathrm{Cd}^{2+}$ and $\mathrm{Fe}^{2+}$ from aqueous solution using waste boiler 
fly ash. Terrestrial and Aquat. Environ. Toxicol., 2(1): 49-53.

Okoye AI, Ejikeme PM, Onukwuli OD. 2010. Lead removal from wastewater using fluted pumpkin seed shell activated carbon: Adsorption modeling and Kinetics. Int. J. Environ. Sci. Tech., 7(4): 793-800.

Onundi YB, Mamun AA, Al Khatib MF, Ahmed YM. 2010. Adsorption of copper, nickel and lead ions from synthetic semiconductor industrial wastewater by palm shell activated carbon. Int. J. Environ. Sci. Tech., 7(4): 751-758.

Opeolu BO, Bamgbose O, Arowolo TA, Adetunji MT. 2009. Utilization of maize (Zea mays) cob as an adsorbent for lead removal from aqueous solutions and industrial effluents. African Journal of Biotechnology, 8: 1567-1573.

Qadeer R and Akhtar S. 2005. Kinetics study of lead ion Adsorption on Active carbon. Turk. J. Chem. 29: 95-99.

Ragheb A, Haggag K, El-thalough A. 1989. Preparation and Characterization of carboxymethyl carobin. Acta Polymerica, 21(40): 705-708.

Resmi G, Thampi SG, Chandrakaran S. 2010. Brevundimonas vesicularis: a novel biosorbent for removal of lead from wastewater Int. J. Environ. Sci. Tech., 4(2): 281-288.

Romero-Gonzalez ME, Williams CJ, Gardiner PHE. 2001. Study of the mechanisms of cadmium biosorption by dealginated seaweed waste. Environ. Sci. Tech. 35(14): 3025-3030.

Saueprasearsit P, Nuanjaren M, Chinlapa M. 2010. Biosorption of lead $\left(\mathrm{Pb}^{2+}\right)$ by Luffa cylindrical fibre. Environmental Research Journal, 4(1): 157-166.
Shukla A, Zhang YH, Dubey P, Margrave JL, Shukla SS. 2002. The role of sawdust in the removal of unwanted materials from water. . J. Hazard. Mater., 95(1): 137152.

Urik M, Littera P, Ševc J, Kolenčik M, Černansky S. 2009. Removal of arsenic (V) from aqueous solutions using chemically modified sawdust of spruce (Picea abies): Kinetics and isotherm studies. Intern. J. Environ. Sci. Technol. 6: 451-456.

Uzun I, Guzel F. 2000. Adsorption of some heavy metal ions from aqueous solution by activated carbon and comparison of percent adsorption result of some other adsorptions. Turk. J. Chem., 24: 291.

Vinodhini V, Das N. 2009. Biowaste materials as sorbents to remove Chromium (VI) from aqueous environment- A comparative study. ARPN J. Agric. Biol. Sci., 4(6): 19-23.

Vinodhini V, Das N. 2010. Relevant approach to assess the performance of sawdust as adsorbent of chromium (VI) ions from aqueous solutions. Intern. J. Environ. Sci. Technol., 7(1): 85-92.

Yang J, Volesky B. 1999. Biosorption and elution of uranium with seaweed biomass. In Biohydrometallurgy and the Environment. Toward the mining of the 21st century: International Biohydrometallurgy symposium Proceedings (20th - 23rd June 1999, Ballester, Antonio, Amils Ricardo (eds). Sen Lorenzo De El Escorial, Madrid Spain, p 483.

Zvinowanda CM, Okonkwo JO, Shabalala PN, Agyei NM. 2009. A novel adsorbent for heavy metal remediation in aqueous environments. Int. J. Environ. Sci. Technol., 6(3): 425-434. 